\title{
TINGKAT STRES DAN INDEKS MASSA TUBUH TERHADAP TEKANAN DARAH MAHASISWA
}

\author{
Made Ermayani \\ Program Studi DIII Keperawatan STIKES Dirgahayu Samarinda \\ J1.Pasundan No 21, Samarinda \\ ermayani.made@gmail.com
}

\begin{abstract}
Hypertension is a disease that can occur from a young age. Students who are in the young adult age group with an unhealthy lifestyle are prone to severe hypertension. Many risk factors for hypertension include stress levels and body mass index (BMI). Knowing that matters related to blood pressure can be used as a preventive measure to prevent complications of hypertension. This study was to determine the relationship between stress levels and body mass index with blood pressure in students of STIKES Dirgahayu Samarinda. This quantitative research was a correlation analytic study with a cross sectional study design. Purposive sampling was used for sampling method, and as an analysis, researcher used the Spearman rho test and multiple correlation test. Respondents aged $17-25$ years, mostly female (82\%), low socioeconomic level $(47.1 \%)$, non-smokers (86.8\%), exercising at least once / month $(50.3 \%)$, and have a family history of hypertension $(54.5 \%)$. The majority of respondents' stress levels were included in moderate anxiety (58.2\%), with normal BMI values $(69.3 \%)$, normal systolic blood pressure (61.9\%) and normal diastolic blood pressure (48.1\%). Stress level and body mass index are simultaneously related to blood pressure, both systolic blood pressure and diastolic blood pressure, with a p value of $0.000<0.05$. There is a relationship between stress levels and body mass index with the blood pressure of STIKES Dirgahayu Samarinda students.
\end{abstract}

Keywords: stress levels, body mass index, blood pressure

\section{PENDAHULUAN}

Hipertensi pada umunya terjadi pada lansia, tapi dapat terjadi juga pada usia dewasa muda dan remaja. Flynn (2009) menjelaskan bahwa terjadi pergeseran epidemiologi hipertensi pada usia muda yang terlihat pertama kali dari data analisis National Health and Nutrition Examination Survey (NHANES) di Amerika Serikat. Keenan \& Rosendorf (2011) juga menjelaskan bahwa prevalensi hipertensi pada orang dewasa berusia diatas 18 tahun di Amerika Serikat dari tahun $2005-2008$ adalah 29,9\%. Data Riskesdas tahun
2018 menunjukan bahwa prevalensi hipertensi berdasarkan hasil pengukuran pada penduduk usia $\geq 18$ tahun di Kalimantan Timur sebesar 39,3\% dan merupakan tertinggi kedua di Indonesia. Penelitian oleh Yuliani Hany (2016) menunjukan bahwa mahasiswa fakultas teknik Universitas Diponegoro mengalami prehipertensi sistolik sebanyak $43 \%$ dan prehipertensi diastolik sebanyak 61\%. Sedangkan penelitian oleh Kautsar Fatimah, Syam Aminuddin, \& Salam Abdul (2014) menunjukan bahwa $46,5 \%$ mahasiswa 
Universitas Hasanudin menderita hipertensi (tekanan darah tinggi).

Penyebab hipertensi primer tidak diketahui penyebabnya, tetapi ada beberapa faktor resiko yang dapat mempengaruhi munculnya hipertensi yaitu riwayat keluarga (keturunan), usia, jenis kelamin, etnis, penyakit diabetes, stress, riwayat merokok, obesitas, asupan $\mathrm{NaCl}$ tinggi, alkohol, peningkatan serum lipid, gaya hidup, status sosial ekonomi, dan tingkat pendidikan (Lewis et al., 2011; Black \& Hawks, 2014). Penelitian oleh Yuliani Hany (2016) menunjukan bahwa faktor risiko yang berhubungan dengan tekanan darah sistolik dan tekanan darah diastolik pada mahasiswa fakultas teknik Universitas Diponegoro yaitu jenis kelamin laki - laki, status obesitas Overweight, aktivitas fisik ringan, stres ringan saat mengerjakan tugasakhir, kualitas tidur buruk, merokok, memiliki kebiasaan konsumsi natrium sering, kebiasaan konsumsi lemak sering, kebiasaan konsumsi gula sering dan kebiasaan konsumsi fast food sering. Penelitian oleh Kautsar Fatimah, Syam Aminuddin, \& Salam Abdul (2014) menunjukan bahwa ada hubungan bermakna antara obesitas (berdasarkan IMT) dengan tekanan darah pada mahasiswa Universitas Hasanudin yang menderita hipertensi.

Hipertensi yang terdeteksi pada usia muda dapat mencegah keparahan penyakit hipertensi. Hipertensi merupakan penyakit kronis yang memerlukan pengelolaan dalam mengontrol tekanan darah. Penderita hipertensi dapat mengelola tekanan darah jika mengetahui faktor risiko yang menyebabkan hipertensi, sehingga dapat mengontrol tekanan darahnya dan mencegah komplikasi hipertensi.

\section{METODE}

Penelitian yang dilaksanakan merupakan penelitian kuantitatif dengan jenis penelitian adalah penelitian analitik korelasi dengan rancangan cross sectional study. Metode sampling yang digunakan adalah purposive sampling. Total jumlah mahasiswa tahun akademik 2018/2019 adalah 436 mahasiswa, jumlah sampel yang digunakan dalam penelitian ini berjumlah 189 orang. Pengumpulan data menggunakan instrumen pengukuran tekanan darah, lembar observasi dan kuesioner. Uji validitas dan reliabilitas kuisioner dilakukan sebelum penelitian dimulai. Uji validitas dan reliabilitas dilakukan pada 30 mahasiswa yang diambil secara acak. Analisa data menggunakan uji spearman rho, dan uji korelasi ganda.

HASIL

\section{A. Analisis Karakteristik Responden}

\section{Tabel 1. Karakteristik Responden}

Karakteristik Responden Jumlah

\begin{tabular}{|c|c|c|}
\hline & $\mathbf{n}$ & $(\%)$ \\
\hline \multicolumn{3}{|l|}{ Jenis Kelamin } \\
\hline Laki-laki & 34 & (18) \\
\hline Perempuan & 155 & 82) \\
\hline \multicolumn{3}{|l|}{ Status Sosial Ekonomi } \\
\hline Rendah & 89 & 47,1 \\
\hline Cukup & 78 & 41,3 \\
\hline Tinggi & 22 & 11,6 \\
\hline \multicolumn{3}{|l|}{ Riwayat Merokok } \\
\hline Tidak Merokok & 164 & 86,8 \\
\hline Perokok Pasif & 9 & 4,8 \\
\hline Merokok $<10$ batang/hari & 16 & 8,5 \\
\hline \multicolumn{3}{|l|}{ Tingkat Aktivitas } \\
\hline Tidak pernah olahraga & 23 & 12,2 \\
\hline Olahraga minimal 1x/bulan & 95 & 50,3 \\
\hline \multicolumn{3}{|l|}{ Riwayat Keluarga } \\
\hline Ada Riwayat Keluarga Hipertensi & 103 & 54,5 \\
\hline Tidak Ada Riwayat Keluarga & 86 & 45,5 \\
\hline
\end{tabular}


Hipertensi

Tingkat Stres

Stres Sedang

Stres Berat

$110 \quad 58,2$

Indeks Masa Tubuh

Kurus

7941,8

Normal

$8 \quad 4,2$

Gemuk

$131 \quad 69,3$

Obesitas

$30 \quad 15,9$

$20 \quad 10,6$

Sumber: Data primer, 2018

Analisis karakteristik responden berdasarkan usia menunjukan bahwa seluruh responden termasuk dalam klasifikasi masa remaja akhir yaitu usia 17 - 25 tahun; responden dengan jenis kelamin perempuan lebih banyak daripada jenis kelamin laki-laki; mayoritas tingkat sosial ekonomi responden berada pada tingkat sosial ekonomi rendah dan tingkat sosial ekonomi cukup; mayoritas responden merupakan bukan perokok; mayoritas tingkat aktivitas responden adalah olahraga minimal $1 \mathrm{x} /$ bulan; sebagian besar responden memiliki riwayat keluarga hipertensi; mayoritas tingkat stres responden termasuk dalam ansietas sedang; dan mayoritas indeks masa tubuh responden normal.

\section{B. Karakteristik Tekanan Darah}

Tabel 2. Tekanan Darah Responden

\begin{tabular}{lllll}
\hline \multirow{2}{*}{$\begin{array}{l}\text { Klasifikasi } \\
\text { Tekanan } \\
\text { Darah }\end{array}$} & \multicolumn{2}{l}{$\begin{array}{l}\text { Tekanan } \\
\text { Darah }\end{array}$} & \multicolumn{2}{l}{$\begin{array}{l}\text { Tekanan } \\
\text { Darah }\end{array}$} \\
& Sistolik & \multicolumn{2}{l}{ Diastolik } \\
\cline { 2 - 5 } & F & $\%$ & F & $\%$ \\
\hline Normal & 117 & 61,9 & 91 & 48,1 \\
Prehipertensi & 64 & 33,9 & 70 & 37 \\
$\begin{array}{l}\text { Hipertensi } \\
\text { Stadium 1 }\end{array}$ & 7 & 3,7 & 21 & 11,1 \\
$\begin{array}{l}\text { Hipertensi } \\
\text { Stadium 2 }\end{array}$ & 1 & 0,5 & 7 & 3,7 \\
\hline Total & 189 & 100 & 189 & 100 \\
\hline \multicolumn{5}{c}{ Sumber: Data primer, 2018 }
\end{tabular}

Tabel 2 menjelaskan bahwa mayoritas responden memiliki tekanan darah sistolik normal dan mayoritas juga memiliki tekanan darah diastolik normal. Hasil penelitian ini sama dengan hasil penelitian Abaa, Polii \& Wowor (2017) yang mendapatkan hasil bahwa sebagian besar mahasiswa di Universitas Sam Ratulangi memiliki tekanan darah sistolik dan diastolik dalam kategori normal.

Tekanan darah adalah adalah kekuatan yang diberikan oleh darah melawan dinding pembuluh darah (Lewis et al., 2011). Tekanan sistolik adalah tekanan maksimal darah melawan dinding arteri ketika jantung berkontraksi (normal 100-140 $\mathrm{mmHg}$ ). Tekanan diastolik adalah tekanan arteri saat jantung berada pada fase relaksasi (normal 60-90 $\mathrm{mmHg}$ ). Tekanan darah dinyatakan sebagai tekanan sistolik/distolik (Black \& Hawks, 2014). Tekanan darah responden yang sebagian besar dalam kategori normal disebabkan karena usia responden yang tergolong usia remaja akhir. Faktor usia berhubungan dengan kualitas pembuluh darah yang masih elastis sehingga tekanan darah masih normal. Risiko hipertensi meningkat bermakna sejalan dengan bertambahnya usia. Beberapa faktor yang dapat meningkatkan tekanan darah terkait dengan bertambahnya usia yaitu peningkatan kekakuan arteri (terutama pada arteri besar); penurunan sensitivitas baroreseptor; peningkatan aktivitas sistem saraf simpatik; disfungsi endotel; penurunan sensitivitas natrium (penurunan kemampuan untuk mengeluarkan natrium); aktivitas renin plasma yang rendah; resistensi insulin; dan efek yang dihasilkan pada metabolisme karbohidrat. Aldosteron juga disebutkan dapat menjadi kontributor yang signifikan untuk terjadinya hipertensi pada usia lanjut 
(Rahajeng \& Tuminah 2009; Khitas \& Supiano, 2015).

Tabel 2 juga menunjukan bahwa ada sebanyak 64 orang $(33,9 \%)$ responden yang memiliki tekanan darah sistolik yang termasuk dalam prehipertensi dan ada sebanyak 70 orang (37\%) responden yang memiliki tekanan darah diastolik yang termasuk dalam prehipertensi. Penelitian Senthil \& Krishndasa (2015) mendapatkan hasil bahwa dari 84 responden mahasiswa berusia 18 - 23 tahun, terdapat 50\% mahasiswa yang memiliki golongan tekanan darah prehipertensi. Prehipertensi merupakan prekursor terjadinya hipertensi dan dapat menyebabkan penyakit kardiovaskular (Chobanian et al cit Senthil \& Krishndasa, 2015). Hipertensi merupakan kondisi dimana tekanan darah sistolik pada level $\geq 140 \mathrm{mmHg}$ dan tekanan darah diastolik pada level $\geq$ 90 mmHg (Black \& Hawks, 2014). Hipertensi pada umunya terjadi pada lansia, tapi dapat terjadi juga pada usia dewasa muda dan remaja. Penelitian oleh Yuliani Hany (2016) menunjukan bahwa mahasiswa fakultas teknik Universitas Diponegoro mengalami prehipertensi sistolik sebanyak $43 \%$ dan prehipertensi diastolik sebanyak $61 \%$. Sedangkan penelitian oleh Kautsar Fatimah, Syam Aminuddin, \& Salam Abdul (2014) menunjukan bahwa 46,5\% mahasiswa Universitas Hasanudin menderita hipertensi (tekanan darah tinggi).

\section{Analisis Hubungan Antara Tingkat Stress Dengan Tekanan Darah}

Tabel 3. Hubungan Antara Tingkat Stress Dengan Tekanan Darah

\begin{tabular}{lll}
\hline Variabel & Nilai & Nilai \\
& korelasi & Signifikan \\
\hline
\end{tabular}

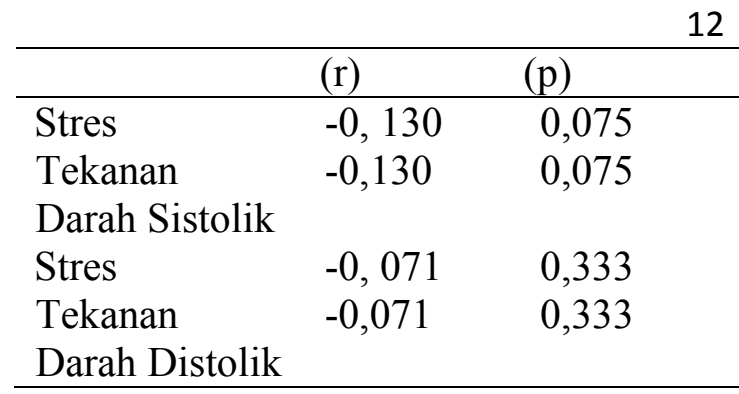

Sumber: Data primer, 2018

Uji korelasi Spearman's rho seperti yang dapat dilihat pada tabel 3 menghasilkan angka korelasi $r=-0,130$ dengan $p=0,075(p>0,05)$. Hasil ini menunjukan bahwa tidak ada hubungan tingkat stress dengan tekanan darah sistolik. Sedangkan uji korelasi Spearman's rho menghasilkan angka korelasi $r=-0,071$ dengan $p=0,333$ ( $p$ $>0,05)$ yang menunjukan bahwa tidak ada hubungan tingkat stress dengan tekanan darah diastolik. Berdasarkan hal tersebut maka dapat disimpulkan bahwa tidak ada hubungan yang bermakna antara tingkat stres dengan tekanan darah sistolik maupun diastolik. Nilai korelasi yang negatif menunjukan bahwa ketika tingkat stress berkurang, maka tekanan darah juga tidak semakin baik (normal). Hasil penelitian ini sama dengan hasil penelitian Pontoh, Kandou \& Mayulu (2016) yang mendapatkan hasil bahwa tidak ada hubungan yang bermakna antara stress dengan kejadian hipertensi. Namun hasil penelitian ini berbeda dengan hasil penelitian Sagare, Rajderkar \& Girigosavi (2011) yang menunjukan bahwa stres mental mempunyai hubungan yang signifikan dengan hipertensi. Cheung et al (2005) menjelaskan bahwa stres dan hipertensi merupakan dua hal yang saling mempengaruhi. Hipertensi dapat menyebabkan gangguan psikologis seperti stres, dan masalah psikologis juga dapat menjadi faktor risiko yang mengembangkan hipertensi. 
Asumsi peneliti terhadap tidak adanya hubungan antara tingkat stress dengan tekanan darah adalah stres yang dialami responden tidak dialami berkepanjangan atau dapat segera diatasi oleh responden sehingga tidak menimbulkan efek ke tekanan darah. Pontoh, Kandou \& Mayulu (2016) menjelaskan bahwa stres memang dapat meningkatkan tekanan darah untuk sementara waktu atau mendadak dan bila stres sudah hilang maka tekanan akan menjadi normal. Setiap manusia memiliki kemampuan untuk mengendalikan respon relaksasinya dengan memikirkan hal-hal yang menyenangkan dan bernapas secara teratur sehingga stres dapat cepat teratasi. Selain itu tidak semua responden memiliki tekanan darah tinggi (hipertensi) dan usia responden yang masih tergolong remaja akhir. Usia yang masih muda berkaitan dengan kualitas pembuluh darah yang masih baik yang mempengaruhi mekanisme tekanan darah.

\section{Analisis Hubungan Antara Indek Masa Tubuh (IMT) Dengan Tekanan Darah}

Tabel 4. Hubungan Antara IMT Dengan Tekanan Darah

\begin{tabular}{llc}
\hline Variabel & $\begin{array}{l}\text { Nilai } \\
\text { korelasi } \\
(\mathrm{r})\end{array}$ & $\begin{array}{l}\text { Nilai } \\
\text { Signifikan } \\
(\mathrm{p})\end{array}$ \\
\hline IMT & 0,347 & 0,000 \\
$\begin{array}{l}\text { Tekanan Darah } \\
\text { Sistolik }\end{array}$ & 0,347 & 0,000 \\
IMT & 0,309 & 0,000 \\
Tekanan Darah & 0,309 & 0,000 \\
Diatolik & & \\
\hline
\end{tabular}

Sumber: Data primer, 2018

Uji korelasi Spearman's rho menghasilkan angka korelasi $r=0,347$ dengan $p=0,000(p<0,05)$. Hasil ini menunjukan bahwa ada hubungan IMT dengan tekanan darah sistolik. Sedangkanangka korelasi $r=0,309$ dengan $p=0,000(p<0,05)$ yang menunjukan bahwa ada hubungan IMT dengan tekanan darah diastolik. Berdasarkan hal tersebut maka dapat disimpulkan bahwa ada hubungan yang bermakna antara IMT dengan tekanan darah sistolik maupun diastolik. Nilai korelasi yang positif menunjukan bahwa semakin nilai IMT kearah normal maka tekanan darah juga semakin baik (normal). Hasil penelitian ini sesuai dengan hasil penelitian Papathanasiou et al (2015) pada 1249 mahasiswa berusia 19 - 30 tahun, yang mendapatkan hasil bahwa IMT mempunyai hubungan yang signifikan terhadap tekanan darah sistolik dan diastolik. Pada table 5.7 dapat terlihat bahwa ada sebanyak 30 responden $(15,9 \%)$ yang memiliki indeks masa tubuh gemuk dan sebanyak 20 responden $(10,6 \%)$ yang memiliki indeks masa tubuh obesitas. Obesitas merupakan salah satu faktor risiko terjadinya peningkatan tekanan darah.

Penelitian oleh Abed \& AbdulHaddaf (2013) menemukan bahwa faktor risiko kedua paling umum yang dapat diubah adalah obesitas $(67,5 \%$ vs $29,2 \%)$ yaitu indek massa tubuh (Body mass index $) \geq 30 \mathrm{~kg} / \mathrm{m}^{2}$. Analisis logistik mulitiple dengan mengontrol usia menunjukkan bahwa prediktor signifikan dari hipertensi salah satunya adalah obesitas. Penelitian oleh Wang et al (2006) juga menunjukan bahwa obesitas merupakan faktor risiko yang signifikan dari hipertensi. Lelong et al (2014) menambahkan bahwa body mass index (BMI) adalah parameter paling penting yang berkaitan dengan tingkat tekanan darah sistolik.

Mufunda et al (2006) menemukan Body mass index $(\mathrm{BMI}) \geq 30 \mathrm{~kg} / \mathrm{m}^{2}$ 
mempunyai hubungan positif dengan tekanan darah sistolik (SBP), diastolik dan mean arterial pressure. Meskipun prevalensi obesitas $(3,3 \%)$ lebih tinggi pada wanita, efek BMI pada tekanan darah lebih tinggi pada laki-laki daripada perempuan (koefisien regresi 0,64 dan $0,38, \mathrm{P} \leq 0,05)$, terutama pada mereka yang berusia $>45$ tahun. BMI tidak memiliki pengaruh yang signifikan terhadap tekanan darah pada orang kurus (BMI < 19) dan pada mereka dengan BMI normal, tetapi berkorelasi positif dengan tekanan darah sistolik pada mereka yang mempunyai BMI tinggi ( $\mathrm{P}$ $\leq 0,02)$.

\section{E. Analisis Hubungan Tingkat Stress Dan Indek Masa Tubuh Dengan Tekanan Darah}

Tabel 5. Hubungan Tingkat Stres dan IMT Dengan Tekanan Darah

\begin{tabular}{llll}
\hline Variabel & $\begin{array}{l}\text { Koefisien } \\
\text { korelasi } \\
\text { (R) }\end{array}$ & $\begin{array}{l}\mathrm{R} \\
\text { Square }\end{array}$ & $\begin{array}{l}\text { sig. F } \\
\text { change }\end{array}$ \\
\hline $\begin{array}{l}\text { Tingkat } \\
\text { Stres, }\end{array}$ & 0,366 & 0,134 & 0,000 \\
IMT & & & \\
dengan & & & \\
Tekanan & & & \\
darah & & & \\
Sistolik & & & \\
Tingkat & 0,329 & 0,108 & 0,000 \\
Stres, & & & \\
IMT & & & \\
dengan & & & \\
Tekanan & & & \\
Darah & & & \\
Diastolik & & & \\
\hline
\end{tabular}

Sumber: Data primer, 2018

Berdasarkan tabel 5. diketahui bahwa besarnya hubungan antara tingkat stress dan indek masa tubuh (secara simultan) dengan tekanan darah sistolik yang dihitung dengan koefisien korelasi adalah 0,366. Sedangkan hubungan antara tingkat stress dan indek masa tubuh (secara simultan) dengan tekanan darah diastolik yang dihitung dengan koefisien korelasi adalah 0,329. Hal tersebut menunjukan hubungan yang sedang antara tingkat stress dan indek masa tubuh (secara simultan) dengan tekanan darah. Kontribusi atau sumbangan secara simultan variabel tingkat stress dan indek masa tubuh terhadap tekanan darah sistolik adalah $13,4 \%$ sedangkan $86,6 \%$ ditentukan oleh variabel lain. Sedangkan kontribusi atau sumbangan secara simultan variabel tingkat stress dan indek masa tubuh terhadap tekanan darah diastolik adalah $10,8 \%$ sedangkan $89,2 \%$ ditentukan oleh variabel lain. Table 5 juga menunjukan bahwa nilai probabilitas (sig. F change) adalah 0,000 . Nilai sig. F change $0,000<0,05$ maka keputusannya adalah Ho ditolak dan Ha diterima, yang artinya adalah tingkat stress dan indek masa tubuh berhubungan secara simultan dengan tekanan darah baik itu tekanan darah sistolik maupun tekanan darah diastolik responden yaitu mahasiswa STIKES Dirgahayu.

\section{PEMBAHASAN}

Tekanan darah dipengaruhi oleh banyak faktor. Pemeliharan tekanan darah normal dan perfusi jaringan membutuhkan integrasi antara faktor sistemik dan pengaruh vaskular perifer lokal. Tekanan darah arteri merupakan suatu fungsi dari cardiac output (CO) dan resistensi vaskuler sistemik. Cardiac output (CO) merupakan total aliran darah melalui sirkulasi pulmonal dan sistemik dalam satu menit. Systemic vascular resistence/ resistensi vaskuler sistemik (SVR) adalah kekuatan melawan gerakan darah dalam pembuluh darah. Jari-jari arteri kecil dan arteriol 
adalah faktor utama yang menentukan resistensi vaskuler. Perubahan kecil pada jari-jari arteriola menyebabkan perubahan besar dalam SVR. Jika SVR meningkat dan $\mathrm{CO}$ tetap konstan atau meningkat, maka tekanan darah arteri akan meningkat (Lewis et al., 2011).

Mekanisme yang mengatur tekanan darah dapat mempengaruhi $\mathrm{CO}$ atau SVR atau keduanya. Pengaturan tekanan darah adalah suatu proses yang kompleks meliputi mekanisme jangka pendek dan jangka panjang. Mekanisme jangka pendek meliputi sistem saraf simpatis, dan endotelium pembuluh darah yang aktif dalam beberapa detik. Mekanisme jangka panjang meliputi ginjal dan hormonal yang mengatur resistensi arteriola dan volume darah (Lewis et al., 2011). Ketika mekanisme ini terganggu maka akan terjadi peningkatan tekanan darah atau disebut hipertensi.

Penyebab hipertensi primer tidak diketahui penyebabnya, tetapi ada beberapa faktor resiko yang dapat mempengaruhi munculnya hipertensi. Faktor risiko terjadinya hipertensi adalah riwayat keluarga (keturunan), usia, jenis kelamin, etnis, penyakit diabetes, stress, riwayat merokok, obesitas, asupan $\mathrm{NaCl}$ tinggi, alkohol, peningkatan serum lipid, gaya hidup, status sosial ekonomi, dan tingkat pendidikan (Lewis et al., 2011; Black \& Hawks, 2014). Pada penelitian ini hanya manganalisis hubungan faktor risiko IMT dan tingkat stress terhadap tekanan darah yang hasilnya menunjukan bahwa IMT dan tingkat stress hanya berkontribusi secara simultan sebesar 13,4 \% terhadap tekanan darah sistolik dan sebesar 10,8\% terhadap tekanan darah diastolik. Hal ini disebabkan karena banyak faktor yang dapat mempengaruhi peningkatan tekanan darah. Oleh sebab itu maka dibutuhkan penelitian lebih lanjut untuk menganalisi factor risiko utama yang mempengaruhi tekanan darah responden terutama responden yang tekanan darahnya dalam klasifikasi prehipertensi, hipertensi stadium 1 dan hipertensi stadium 2.

Hasil penelitian ini menunjukan bahwa terdapat responden yang tekanan darahnya dalam klasifikasi prehipertensi, hipertensi stadium 1 dan hipertensi stadium 2. Hipertensi tidak hanya menjadi masalah bagi orang dewasa dan lansia tetapi hipertensi juga merupakan suatu masalah pada remaja. Remaja yang mengalami hipertensi dapat terus berlanjut pada usia dewasa dan memiliki risiko morbiditas dan mortalitas yang lebih tinggi. Walaupun prevalensi secara klinis sedikit pada remaja dibanding pada dewasa, namun cukup banyak bukti yang menyatakan bahwa hipertensi esensial pada orang dewasa dapat berawal pada masa kanak - kanak dan remaja (Candra, Wijayanti \& Nissa, 2017).

\section{SIMPULAN DAN SARAN}

Tingkat stress dan indek masa tubuh berhubungan secara simultan dengan tekanan darah baik itu tekanan darah sistolik maupun tekanan darah diastolic. Diharapkan lingkungan kampus sebagai tempat mahasiswa belajar dapat memfasilitasi mahasiswa dalam upaya mengurangi tingkat stress dan mengelola berat badan agar tidak terjadi peningkatan IMT. Selain itu diharapkan kegiatan yng terkait dengan aktivitas fisik (olahraga) juga perlu ditingkat, hal ini terkait dengan pengelolan berat badan yang berhubungan dengan indek massa tubuh mahasiswa. Peneliti selanjutnya dapat menganalisis lebih dalam faktor - faktor yang paling mempengaruhi tekanan darah pada mahasiswa, terutama tentang gaya hidup yaitu pola makan. Hal ini 
terkait dengan kondisi mahasiswa yang lebih banyak tidak tinggal dengan orang tua, sehingga konsumsi makanan lebih sering dengan membeli makanan yang cepat saji.

\section{DAFTAR PUSTAKA}

Abaa Yoel P, Polii Hedison, Wowor Pemsi M. (2017). Gambaran Tekanan Darah, Indeks Massa Tubuh, dan Aktivitas Fisik pada Mahasiswa Kedokteran Umum Angkatan Tahun 2014. Jurnal eBiomedik (eBm), Volume 5, Nomor 2 Juli - Desember 2017. https://ejournal.unsrat.ac.id/index.p hp/ebiomedik/article/view/18509/1 8037

Abed \& Abdul-Haddaf. (2013). Risk Factors of Hypertension at UNRWA Primary Health Care Centers in Gaza Governorates. Hindawi Publishing Corporation, ISRN Epidemiology Volume 2013. Diperoleh pada tanggal 1 Februari 2015 dari www.hindawi.com.

Black \& Hawks. (2014). Keperawatan Medikal Bedah; Manajemen Klinis untuk Hasil yang Diharapkan-edisi 8. Penerbit Elsevier; Singapura

Candra, A. (2017). Hubungan Asupan Zat Gizi dan Indeks Antropometri dengan Tekanan Darah Remaja. JNH (Journal of Nutrition and Health), 5(2), 85-101. https://doi.org/10.14710/jnh.5.2.20 17.85-101.

https://ejournal.undip.ac.id/index.p hp/actanutrica/

Cheung et al. (2005). The Relationship Between Hypertension And Anxiety Or Depression In Hong Kong Chinese. Experimental Clinical Cardiology Volume 10, Number.
Diperoleh pada tanggal 16 Januari 2015 dari www.ncbi.nlm.nih.gov.

Flynn, J.T. (2009). Hypertension in the young: epidemiology, sequelae and therapy. Nephrology, Dialysis, Transplantation Journal Volume 24, Issue 2, Pages 370-375. Diperoleh pada tanggal 20 Agustus 2015 dari ndt.oxfordjournals.org

Kautsar Fatimah, Syam Aminuddin, \& Salam Abdul. (2014). Obesitas, Asupan Natrium Dan Kalium Terhadap Tekanan Darah. Jurnal MKMI, Desember 2014, hal 187192.http://journal.unhas.ac.id/index .php/mkmi/article/view/491/304

Keenan NL, Rosendorf KA; Centers for Disease Control and Prevention (CDC). Prevalence of hypertension and controlled hypertension United States, 2005-2008. MMWR Suppl. 2011;60(1):94-97.

Kithas, P. A., \& Supiano, M. A. (2015). Hypertension in the geriatric population: a patient-centered approach. The Medical clinics of North America, 99(2), 379-389. https://doi.org/10.1016/j.mcna.201 4.11.009

Lelong et al. (2014). Relationship Between Nutrition and Blood Pressure: A Cross-Sectional Analysis from the NutriNet-Santé Study, a French Web-based Cohort Study. American Journal of Hypertension, Volume 28, Issue 3. Diperoleh pada tanggal 26 Januari 2015 dari ajh.oxfordjournals.org/

Lewis et al. (2011). Medical Surgical Nursing: Assessment and Management of Clinical Problems. USA. Penerbit Elsevier; Singapura

Mufunda et al. (2006). The prevalence of hypertension and its relationship with obesity: results from a national blood pressure survey in Eritrea. Journal of Human 
Hypertension Volume 20, Pages 59-65. Diperoleh pada tanggal 1 Februari 2015 dari www.ncbi.nlm.nih.gov

Papathanasiou, G., Zerva, E., Zacharis, I., Papandreou, M., Papageorgiou, E., Tzima, C., ... Evangelou, A. (2015). Association of high blood pressure with body mass index, smoking and physical activity in healthy young adults. The open cardiovascular medicine journal, 9 , 5-17. doi:10.2174/187419240150901000 5

Pontoh, L.W., Kandou, G.D., \& Mayulu, N. (2016). Hubungan Antara Obesitas, Konsumsi Natrium, Dan Stres Dengan Kejadian Hipertensi Pada Orang Dewasa Di Puskesmas Tompaso Kabupaten Minahasa.

Rahajeng, Ekowati dan Sulistyowati Tuminah. (2009). Prevalensi Hipertensi dan Determinannya di Indonesia. Majalah Kedokteran Indonesia Vol.59 : 12, halaman 580-587.

http://egiwidiyaoktora201432049. weblog.esaunggul.ac.id/wpcontent/uploads/sites/4896/2015/09 1700-760-1-PB.pdf

RISKESDAS. (2018). Riset Kesehatan Dasar Tahun 2018. Badan Penelitian Dan Pengembangan Kesehatan, Kementerian Kesehatan RI. Diperoleh pada tanggal 21 Juni 2018 dari www.depkes.go.id

Sagare, Rajderkar \& Girigosavi. (2011). Certain Modifiable Risk Factors In Essential Hypertension: A Casecontrol Study. National Journal Of Community Medicine, Volume 2, Issue 1. Diperoleh pada tanggal 1 Februari 2015 dari www.njemindia.org
Senthil, S., \& Krishndasa, S. N. (2015). Pre-Hypertension in Apparently Healthy Young Adults: Incidence and Influence of Haemoglobin Level. Journal of clinical and diagnostic research: JCDR, 9(11), CC10-CC12.

doi:10.7860/JCDR/2015/14970.68

47. diperoleh pada tanggal 10

November dari

https://www.ncbi.nlm.nih.gov

Wang et al. (2006). A Longitudinal Study of Hypertension Risk Factors and Their Relation to Cardiovascular Disease: The Strong Heart Study. American Heart Association Journal, Volume 47, Pages 403-409. Diperoleh pada tanggal 1 Februari 2015 dari hyper.ahajournals.org

Yuliani, H., Santoso, H., Adi, M., \& Saraswati, L. (2016). Gambaran Faktor Risiko Aktivitas Fisik, Kualitas Tidur, Dan Stres Dengan Tekanan Darah Pada Mahasiswa Tingkat Akhir Fakultas Teknik Universitas Diponegoro. Jurnal Kesehatan Masyarakat (eJournal), 4(4), 387-393. Retrieved from https://ejournal3.undip.ac.id/i ndex.php/jkm/article/view/14160 